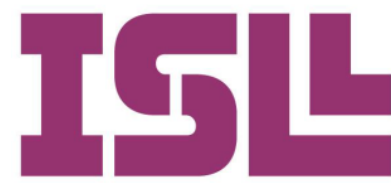

Número 7.

Enero de 2017

\section{Booktrailer y Booktuber como herramientas LIJ 2.0 para el desarrollo del hábito lector}

\section{Booktrailer and Booktuber as LIJ 2.0 tools for development of reading habits}

\author{
José Rovira-Collado \\ Dept. Innovación y Formación Didáctica \\ Universidad de Alicante
}

Pág. 55 a la 72

Keywords

Social Reading, Booktrailer, Booktuber, Internet

\begin{abstract}
:
In the most recent formulas to promote reading, we focus on two dynamics that offer us many possibilities in schools to encourage reading habits of our students. Are Booktrailer, audiovisual books publicity like cinema and Booktuber, video reviews of the latest readings mainly young people shared across different Internet tools. New digital devices have favored recording, editing and publishing video, so the audiovisual and multimedia format becomes the perfect ally of reading. This paper want to do a description of both concepts, considering their advantages and disadvantages and especially the many possibilities of implementation in the educational field to work reading comprehension. For this show, various examples of good practices both dynamics to ensure that these digital products are an ideal support for the development of reading habits among students.
\end{abstract}





\section{Introducción}

Dada la imparable evolución de la tecnología, los formatos audiovisuales se están generalizando en todos los ámbitos de la práctica didáctica. Para trabajar el hábito lector han aparecido dos nuevos conceptos, los Booktrailer y los Booktuber, estrechamente ligados con la promoción de la lectura y con la literatura infantil y juvenil en Internet o LIJ 2.0. Ambos formatos cuentan ya con una amplia difusión en la red, como una práctica habitual de la mayoría de las editoriales para la promoción de sus obras, o a través de los canales de jóvenes youtubers con miles de seguidores y seguidoras que demuestran que en la red también se habla de libros. En el siguiente trabajo, más allá de conocer alguna de estas prácticas de animación a la lectura, mostraremos las posibilidades de ambos formatos como instrumento didáctico en la formación docente, especialmente en el ámbito de la literatura infantil y juvenil y la competencia lecto-literaria.

\subsection{Dos nuevos formatos para la promoción de la lectura}

Con la rápida evolución e implantación de las herramientas digitales de interacción social (móviles, tabletas, libros electrónicos...) y con la ampliación del acceso de banda a Internet (4G o Fibra óptica), nos encontramos con nuevas dinámicas en el acceso a la lectura y la difusión de esta, con nuevos conceptos como la Lectura Social o Lectura 2.0 (Cordón et alii, 2013 y Lluch, 2014a) o la LIJ 2.0 (Rovira-Collado, 2011). Estas nuevas formas de participación permiten a cualquier persona compartir sus lecturas a través de vídeos en Internet. Las propuestas de creación audiovisual en nuestra práctica docente son cada vez más amplias (Giráldez, 2015) y no debemos considerarlas un enemigo del desarrollo del hábito lector. De entre las nuevas propuestas hay dos formatos que conjugan a la perfección las nuevas posibilidades audiovisuales y multimodales con la lectura literaria. En primer lugar los Booktuber, reseñas literarias en formato vídeo que nos ofrecen las impresiones de sus lectores. Utilizaremos este término para referirnos tanto a las personas que realizan dichos vídeos como para los propios vídeos en sí. En segundo lugar, los Booktrailer, como propuestas de promoción multimedia de las obras literarias que pueden utilizarse como estrategia publicitaria de una editorial o como propuesta didáctica. Estamos dentro de una nueva evolución digital de los medios audiovisuales y debemos aprovecharla en nuestras propuestas didácticas: "composing using a medium like YouTube can help involve students in their own learning process" (Limbu y Gurung, 2014, p.95).

\subsection{De la lectura social a la práctica docente}

Ambas formas de participación permiten compartir sus lecturas a cualquier persona con una cámara digital y acceso a Internet, de muy diversas maneras y también conocer muchas obras de una manera rápida y eficaz. Son elementos propios de lo que se ha definido como Literatura y Lectura Infantil y Juvenil en la Web Social o LIJ 2.0 ya que aprovechan las dinámicas de participación de la Web 2.0 para transmitir la literatura de maneras distintas a las que se habían conocido hasta ahora, dándose estas dinámicas principalmente en un

ISL, vol. 7, 2017, págs. 55-72 ISSN: $2340-8685$
Collado Rovira, J. (2017): Booktrailer y Booktuber como herramientas LIJ 2.0 para el desarrollo del hábito lector, Investigaciones Sobre Lectura, 7, 55-72. 
público infantil y juvenil. Dentro de la LIJ 2.0, es fundamental el concepto de lectura social y colaborativa: "La lectura social o colaborativa es aquella que se desarrolla en plataformas virtuales configurando una comunidad que desarrolla formas de intercambio diversas, compartiendo comentarios, anotaciones, valoraciones, etiquetas y, en algunos casos, libros y lecturas." (Cordón y Gómez, 2013). Desde una perspectiva teórica y siguiendo a Genette, podemos definir estos elementos paratextuales como epitextos (Tabernero, 2013 y 2016; Tabernero, Lluch y Calvo, 2015) porque están fuera de la obra literaria, pero nos ofrecen mucha información sobre ella y nos ayudan en la promoción de su lectura. Aunque la mayor parte del consumo de estos productos se realiza fuera del aula y de las tareas escolares, es hora de que se conviertan en práctica habitual del profesorado. Gemma Lluch afirma que:

Muchas de las actividades que hacen en Internet, como compartir, leer, redactar, organizar, buscar, valorar, clasificar o utilizar archivos multimedia, podemos utilizarlas para leer y escribir sobre las lecturas, para compartirla con conocidos o desconocidos, para aprender, para crear una comunidad unida por la lectura (Lluch, 2011, p.91).

Entre las nuevas metodologías educativas podemos destacar el Aprendizaje Basado en Proyectos (ABP) que se centra en la creación de contenidos por parte del estudiante a través de proyectos concretos para cada asignatura y etapa educativa. En este sentido, para este enfoque es fundamental que el resultado de cada proyecto tenga una proyección fuera del aula, como pueden ser los dos elementos tratados. ). En palabras de Fernando Trujillo (2014) "el ABP tiene que ser una experiencia memorable para todos los participantes", así como "una experiencia vital de aprendizaje significativo". Ambos podemos considerarlos como "artefactos digitales" dentro de la clasificación del grupo Conectal3 [http://artefactosdigitales.com/] (Trujillo et alii, 2015).

\section{Metodología}

\subsection{Participantes}

Como podemos ver en los anexos 1 y 2, donde aparece una amplia muestra de resultados, en la Universidad de Alicante se ha trabajado desde 2012 en distintas asignaturas con ambos formatos audiovisuales para trabajar la LIJ en distintos niveles. Entre 2012 y 2014 se trabajó en primer lugar con el alumnado de una asignatura optativa del Grado de Maestro en Educación Infantil (curso $3^{\circ}$ y $4^{\circ}$ ) para las reseñas audiovisuales y en segundo lugar con el alumnado del Máster de Formación del Profesorado para el booktrailer. El alumnado de estos cursos ya ha cursado distintas asignaturas relacionadas con la formación del lector literario.

En cambio, los resultados recogidos en el Anexo 3 son obra de alumnado del primer curso del grado de Maestro en Educación Infantil y del primer curso de Maestro en Educación Primaria durante el curso 2015-2016. 


\subsection{Instrumentos}

El instrumento central de nuestra investigación es el propio resultado de nuestra práctica docente. Ambos formatos, Booktrailer y Booktuber son productos audiovisuales centrados en la literatura. En todas las propuestas realizadas, objeto de nuestro análisis, nos encontramos con propuestas didácticas que forman parte de las prácticas de distintas asignaturas. Para recopilar las distintas propuestas nos hemos valido de las listas de reproducción de Youtube. Además, varias de las propuestas están publicadas dentro de blogs de asignaturas para mejorar la difusión de las mismas, así como el trabajo de edición digital de nuestro alumnado.

En algunas de las propuestas como la de Uniblogmaniacos 2014 [http://uniblogmaniacos.blogspot.com.es/] se han utilizado encuestas semiestructuradas y rúbricas de evaluación de los vídeos, adaptadas a cada curso o tipo de práctica (Booktrailer o Booktuber).

A continuación, presentamos una serie de referencias y ejemplos, que, además de conformar el marco teórico de nuestra investigación, se han utilizado para presentar ambas prácticas a lo largo de los distintos cursos.

\subsection{Cuando el vídeo encontró al libro: los Booktuber}

Aunque es un movimiento prácticamente nuevo y no se ha identificado quién fue la primera persona en subir a youtube una reseña literaria, se ha consolidado en muy pocos años. Nacido en Estados Unidos, es un fenómeno que está creciendo en la actualidad, aunque es partir de mediados de 2013 cuando se nota su presencia en español (PachecoAlonso, 2014). Sin embargo, como veremos, existen también algunos modelos precedentes como Kuentalibros.

Por su sencillez, podemos considerarlo como el primer espacio de la LIJ 2.0 audiovisual, que recoge miles de experiencias con cientos de miles de reproducciones. Estas reseñas orales, generalizadas bajo el término booktuber, son una evolución hacia el vídeo y la expresión oral de lo que en los blogs se ha denominado como lectura social con amplias posibilidades didácticas (Torrego, 2012 y García y Rubio, 2013). Santiago Carbajo (2014) define así esta tendencia:

Jóvenes, mayormente chicas adolescentes, se ponen delante de una cámara y hablan de los libros que leen. No es el típico haul vlogger que nos comenta inocentemente (o no) sus últimos delirios consumistas relacionados con la moda, la belleza o cualquier cachivache electrónico. Aunque el sistema y la forma de manifestarse ante la audiencia es el mismo, el objeto es diferente: hablamos de libros juveniles y de todo lo que rodea a los mismos.

Es YouTube, una vez más, la plataforma elegida para que jóvenes aficionados a la lectura, heridos por la letra, den rienda suelta a su pasión, a su fetichismo libresco, al placer incipiente del coleccionista de libros (Book Haul). Les gusta mostrar sus maravillosos libros baratos conseguidos en librerías de segunda mano. Nos hablan de los chollos que hay en Internet si queremos comprar buenos libros de aventuras, ciencia ficción o novela romántica.

ISL, vol. 7, 2017, págs. 55-72 ISSN: $2340-8685$
Collado Rovira, J. (2017): Booktrailer y Booktuber como herramientas LIJ 2.0 para el desarrollo del hábito lector, Investigaciones Sobre Lectura, 7, 55-72. 
Son los lectores juveniles los principales protagonistas que comparten la opinión de sus lecturas, siendo una herramienta de promoción editorial importantísima porque además se comunican con sus coetáneos usando su propio lenguaje, donde el dominio de la comunicación audiovisual y la técnica es evidente. Esta moda traslada el fenómeno youtuber al fomento de la lectura y confirma que los jóvenes actuales, muchas veces definidos como "nativos digitales", leen más que nunca. Junto con las redes sociales que también se utilizan como complemento para difundir las grabaciones, han sido los espacios de mayor desarrollo de la LIJ 2.0 en los últimos años. Es un fenómeno en constante crecimiento como podemos confirmar a través de la comunidad de Facebook con más de ocho mil quinientos integrantes [https://www.facebook.com/BooktubeEnEspanol].

En el vídeo "Booktube" el Documental" (diciembre de 2013) [https://www.youtube.com/watch?v=PHQ5pufM_6I], encontramos un rápido panorama del fenómeno y sobre todo del éxito que está teniendo en Latinoamérica a través de la experiencia de varios jóvenes que tienen miles de seguidores. Alberto Villarreal, autor de "Abriendo Libros", un booktuber con más de trece mil suscriptores comenta: "Yo creo que las personas están interesadas en nuestros vídeos porque es algo muy personal. Una persona con una cámara, se siente muy personal, a diferencia de los blogs porque aquí es una persona que da la cara y se siente más como una amistad." Para conocer algunos de los perfiles más destacados e identificar las características principales y la distinta tipología de vídeos y de personas que participan de esta práctica hemos trabajado en el aula con los siguientes ejemplos:

- Fátima Las palabras de Fa. [https://www.youtube.com/user/laspalabrasdefa] Creado en julio de $2012 \mathrm{su}$ canal tiene más de trescientos mil suscriptores y cada vídeo supera rápidamente las cincuenta mil reproducciones. Es posiblemente el principal ejemplo en Hispanoamérica (Sánchez 2015) y se ha convertido en un referente cultural para los adolescentes aficionados a la lectura.

- Javier Ruescas, [https://www.youtube.com/user/ruescasj] es el principal ejemplo de autor y editor que usa todas las herramientas 2.0 para la promoción de sus obras. Su canal tiene casi ciento cincuenta mil suscriptores y más de tres millones de reproducciones y además de críticas de libros incluye consejos editoriales, talleres de escritura y entrevistas.

- Gemma Lienas [https://www.youtube.com/user/gemmalienas] Este es un ejemplo de que la LIJ2.0 no es exclusiva de los jóvenes ya que es una autora con una amplia experencia con más de cincuenta libros publicados.

- Marta Botet [https://www.youtube.com/user/martabotetborras/] es una joven lectora que comenzó su blog con once años [http://recomanacionsdellibres.blogspot.com.es/] y que luego empezó con reseñas audiovisuales que demuestran que también hay espacio para obras 
más infantiles y lectoras más jóvenes. Ha sido tal su relevancia que fue invitada a hablar en una charla TEDYouth en Nueva York sobre su experiencia como Booktuber [https://www.youtube.com/watch? $\mathrm{v}=\mathrm{p}-$ 7zk4BwGmA].

- Sebastián G. Mouret, El Coleccionista de mundos [https://www.youtube.com/user/channelcoleccionista] con más de ciento setenta mil suscriptores y más de seis millones reproducciones, su éxito le ha permitido colaborar con la revista digital de literatura juvenil El tempo de las mil puertas [http://www.eltemplodelasmilpuertas.com/] y ser un referente de muchas personas que empiezan con esta práctica didáctica. Podemos anotar que desde 2015 las cifras de todos ellos se han triplicado.

Aunque podamos encontrar algunas críticas al modelo (Garralón, 2014), sobre todo por la repetición de las obras que se reseñan, muchos superventas juveniles, que en algún caso podemos considerar paraliteratura, y por la falta de profundidad de algunos análisis, obvia también por la etapa formativa de los protagonistas, consideramos los booktubers como una dinámica muy relevante para la promoción lectora ya que muchas veces están haciendo un trabajo entre iguales. Es una dinámica que surge fuera de las aulas escolares y sus principales protagonistas ya se han convertido en estrellas de Internet y no se plantean un fin didáctico. Sin embargo, es necesario llevar estas dinámicas a las aulas. Gemma Lluch (2014b) destaca las posibilidades didácticas de este formato y como los podemos aprovechar para mejorar la expresión oral:

En este post, describimos los pasos que hay que seguir para elaborar un guion que ayude al estudiante a exponer ante un público presencial o virtual la experiencia del libro que ha leído. (...) Las indicaciones están pensadas para un entorno académico, por lo tanto, tienen la finalidad de construir un texto adecuado a la norma y al contexto comunicativo. El objetivo no es ser popular en las redes sociales o entretener a un público (si se consigue mejor, es un plus). La finalidad del trabajo es:

1. aprender a escribir un texto para ser dicho $y$

2. saber escribir un texto como apoyo de la exposición oral.

Limbu y Gurung plantean la utilidad de incorporar esta dinámica en nuestra práctica escolar, ya que permite incrementar el aprendizaje del nuestro alumnado:

Teachers who incorporate the creation of "BookTubers" or other identity-bound grassroots genres into their curriculum could facilitate the interactive, borderless, social, and collaborative possibilities of such an NKC in the classroom environment, thereby increasing learning and engagement through student production of videos and other multimodal texts (Limbu y Gurung, 2014, p.88).

Uno de los proyectos colaborativos más destacados durante los últimos años que también se basaba en las reseñas audiovisuales fue el blog Kuentalibros [http://kuentalibros.blogspot.com.es/]. Es un precedente directo a este fenómeno en la red, pero en este caso con un claro objetivo didáctico (Ambrós, 2015). El proyecto surgió

ISL, vol. 7, 2017, págs. 55-72 ISSN: $2340-8685$
Collado Rovira, J. (2017): Booktrailer y Booktuber como herramientas LIJ 2.0 para el desarrollo del hábito lector, Investigaciones Sobre Lectura, 7, 55-72. 
de un equipo de distintos profesores que empezaron a grabar reseñas de libros para sus clases. Posteriormente el proyecto se abrió a otros centros y cualquier persona podía enviar su vídeo con información para la entrada. Nació en 2011 y fue clausurado en junio de 2013 con casi dos mil entradas y más de un millón de visitas. En las grabaciones encontramos reseñas orales tanto alumnado de primaria, secundaria, bachillerato y estudios superiores, como docentes de todas esas etapas. En el primer anexo encontramos algunas propuestas desde la Universidad de Alicante. Aunque los docentes implicados en Kuentalibros han iniciado otros proyectos, podemos considerar es blog como un hito en la transformación didáctica de la LIJ 2.0 (Asensi, 2015).

\subsection{Libros de película: los Booktrailer.}

En este espacio de desarrollo de la LIJ 2.0 confluyen el cine con la literatura ya que utiliza un medio propio del séptimo arte, el tráiler, para promocionar la lectura de una obra literaria. Un portal catalán especializado los define así [http://www.booktrailer.cat/\#booktrailer]:

Un booktrailer és un petit vídeo publicitari que presenta un llibre, de manera que capti l'interès del lector. És una forma directa perquè els lectors coneguin els llibres que han de llegir. Pot ser amb actors i rodatge, amb videoanimacions i amb qualsevol altre tècnica audiovisual, però el més important és que sigui curt, impactant i de qualitat.

Oficialmente, el primer booktrailer fue creado en 2003 para el libro de vampiros Dark Simphony de Christine Feehan [http://www.youtube.com/watch?v=Hmo4VMcbbXg] pero han pasado más de diez años para que esta práctica se generalice. En Internet encontramos infinidad de propuestas, ya sean repositorios de ejemplos como [http://www.librosyliteratura.es/booktrailer], [http://www.que-leer.com/revista/booktrailers] o [http://www.booktrailer.cat/] o espacios para su creación: [http://blog.soopbook.es/concursos/\%C2\%BFte-atreves-a-crear-un-book-trailer/ o http://www.trailerbookfactory.com/].

Booktrailersweb nos presenta las siguientes características [http://www.booktrailersweb.es/qu\%C3\%A9-es-un-book-trailer/]: Elementos de un booktrailer:

- Entradilla de presentación y editorial

- Textos seleccionados del libro original, bien escritos o narrados.

- Imágenes: Ilustraciones del propio libro. Si no las tiene, se pueden recurrir a otras imágenes para poder hacerse una idea figurada del libro.

- Información sobre el autor

- Información sobre la fecha de lanzamiento y el punto de venta 


\section{Características de un booktrailer}

- Poca duración

- Gran intensidad

- Funciona como un pequeño avance

- Trata de enganchar al público

- Proporciona información: autores, fechas de presentación.

Han sido principalmente las editoriales de LIJ o los propios autores y autoras los que se han lanzado a promocionar los libros de esta manera. Por ejemplo, podemos citar el booktrailer de Croquetas y wasaps de Begoña Oro (Ediciones SM, 2013), [http://www.youtube.com/watch?v=a6UgQy89ar8] o el de El rostro de la sombra de Alfredo Gómez Cerdá (Ediciones SM, 2011), [https://www.youtube.com/watch?v=DbHKQrP1rZw\#t=14] como unos modelos de partida. En 2016 se ha convertido en una práctica habitual que acompaña a cualquier lanzamiento editorial destacado, no solamente en el ámbito de la LIJ y utilizándose para cualquier tipo de publicación.

Respecto a la relación del booktrailer con la obra adaptada Rosa Tabernero (2013) comenta:

En primer lugar, el book trailer, tal y como lo hemos descrito, formaría parte del entorno epitextual del libro tal como lo definía Genette (2001). Se trataría de los paratextos que se mantienen a cierta distancia del libro. Sin embargo, hemos podido comprobar que el book trailer corresponde, sobre todo en la segunda clase que hemos distinguido, a la traducción virtual de peritextos como los textos de contracubierta (Tabernero, 2013, p.218).

Aunque en la concepción son una propuesta publicitaria de las editoriales, consideramos que lo más interesante para la formación lectora es la explotación didáctica y la creación de nuevos ejemplos por parte del alumnado de distintas etapas. En la página del grupo Gretel de la Universidad Autónoma de Barcelona encontramos algunas propuestas del alumnado del Máster en Bibliotecas y Promoción a la Lectura" de booktrailers de obras de LIJ [http://literatura.gretel.cat/es/made-in-gretel/book-trailerslibros-lij]. Los estudiantes del máster de la UAB, crearon los vídeos como parte de un proyecto de aula, una animación lectora, una manera de dinamizar la biblioteca escolar o una forma de variar las recomendaciones de las lecturas o de promocionar las producciones propias del alumnado.

Pero más allá del análisis y aprovechamiento en el aula de las propuestas editoriales, en nuestra opinión el aprovechamiento didáctico más interesante de este formato es la realización de vídeos por parte del alumnado. En el segundo anexo encontramos las propuestas realizadas por el alumnado del Máster de Formación del Profesorado en la Universidad de Alicante durante cuatro cursos académicos.

ISL, vol. 7, 2017, págs. 55-72 ISSN: $2340-8685$
Collado Rovira, J. (2017): Booktrailer y Booktuber como herramientas LIJ 2.0 para el desarrollo del hábito lector, Investigaciones Sobre Lectura, 7, 55-72. 
Es por lo tanto una nueva forma de promoción de la lectura, donde la comunicación digital es fundamental. Un espacio en desarrollo dentro de la Web 2.0 como comenta Rosa Tabernero:

Creemos que el book trailer constituye un medio de promoción del libro infantil y juvenil muy adecuado por utilizar un entorno virtual en el que el lector del siglo XXI se mueve de forma natural. El álbum y el libro ilustrado, por sus características genéricas de hibridación de géneros y lenguajes, resultan especialmente próximos a la dinámica del book trailer. Por esta razón y por la necesidad de utilizar propuestas de promoción de lectura atractivas, necesitamos entender el funcionamiento interno de este instrumento para aventurar, como hemos hecho, en qué medida el book trailer puede convertirse en un instrumento de promoción de la lectura en el ámbito de la Web 2.0, tanto desde la perspectiva de la recepción como desde la creación. Se transforma, por consiguiente, en un recurso valioso de adquisición de competencia literaria dentro y fuera de las aulas (Tabernero, 2013, p. 220).

\section{Resultados}

Antes de continuar es necesario anotar que hemos decidido usar los términos Booktrailer y Booktuber, ya que son los que más presencia tienen en Internet, tanto en el ámbito anglófono como en el español y latinoamericano. Sin embargo podemos encontrar otras propuestas para el primer caso, como Librotráiler o Bibliotráiler, recomendada esta última por la Fundeu (2014). Además en el segundo caso, encontramos un amplio léxico específico para referirse a las distintas dinámicas también con gran influencia del inglés como por ejemplo (LiteraturaSM, 2014 y Revista Babar, 2015):

\footnotetext{
Book Haul / IMM: Repaso a todas las nuevas lecturas que han llegado a las manos del booktuber, ya sean compradas o regaladas. IMM es el acrónimo de In My Mailbox (en mi buzón).

Bookself tour: Repaso por las estanterías del autor del video. Suelen ser barridos de cámara en los que comenta en off algunos de los títulos preferidos de su biblioteca.

Book Tag: Preguntas, juegos, pruebas, memes o retos literarios relacionados con los libros pensados para conocer con mayor profundidad determinados títulos.

Wishlist: Aquellos títulos que se quieren conseguir o que, con impaciencia, se espera su publicación o traducción en español.

Wrap Up: Se utiliza para denominar aquellos libros leídos en un mes por el gestor de los vídeos. Habitualmente se realiza una enumeración de los mismos junto con una breve reseña mientras aparecen en pantalla.
}

Los resultados de este trabajo son las propias propuestas de nuestro alumnado durante los últimos cuatro cursos académicos. Recordemos que las propuestas obtenidas tienen un fin didáctico en el ámbito universitario y no de publicidad como los Booktrailers de editoriales o de promoción personal y de la lectura como los Booktubers más famosos. Los vídeos obtenidos están recogidos en los anexos en tres categorías:

- Anexo 1. Booktuber/Kuentalibros 1.A. TECCAS12 y 1.B. TECCAS13.

- Anexo 2 Booktrailer Máster de Secundaria. 2.A. INVTICUA13 2.B. INVTICUA14; 2.C. INVTICUA15 y 2.D. INVTICUA16.

Collado Rovira, J. (2017): Booktrailer y Booktuber como herramientas LIJ 2.0 para el desarrollo del hábito lector, Investigaciones Sobre Lectura, 7, 55-72. 
- Anexo 3. Booktuber y Booktrailer alumnado primer curso 3.A. 1LLEP15 y 3.B. 1DLCLEI16.

El arco de resultados abarca desde las primeras experiencias en octubre de 2012 hasta propuestas del curso 2015-2016. Hemos identificado cada grupo bajo una etiqueta que hace alusión al curso donde se desarrolló como práctica en el aula y que también fue utilizada para la difusión de los trabajos en Twitter.

El corpus de nuestro análisis comprende casi veinte Booktubers y más de cuarenta Booktrailers realizados por el alumnado de la Universidad de Alicante. De dicha experiencia podemos extrapolar múltiples datos que hemos recogido en la siguiente tabla:

\begin{tabular}{|c|c|c|}
\hline & Booktrailer & Booktuber \\
\hline $\begin{array}{l}\text { Traducción } \\
\text { al español }\end{array}$ & Bibliotráiler & Reseña Audiovisual \\
\hline Duración & $\begin{array}{l}\text { Duración. De } 30 \text { segundos a } 2 \\
\text { minutos. }\end{array}$ & $\begin{array}{l}\text { Duración. Más larga: De } 3 \text { a } 6 \text { minutos, incluso } \\
\text { más. }\end{array}$ \\
\hline Agrupación & Trabajo grupal. & $\begin{array}{l}\text { Trabajo individual } \\
\text { (posibilidad de parejas o grupos pequeños). }\end{array}$ \\
\hline Guion & $\begin{array}{l}\text { Necesidad de Guion. } \\
\text { Storyboard recomendable. }\end{array}$ & $\begin{array}{l}\text { Necesidad de Guion. En las primeras experiencias } \\
\text { se aprende de memoria o directamente se lee. }\end{array}$ \\
\hline $\begin{array}{l}\text { Relevancia } \\
\text { del texto } \\
\text { escrito }\end{array}$ & Texto secundario. & Importancia central del discurso oral. \\
\hline $\begin{array}{l}\text { Formato } \\
\text { audiovisual }\end{array}$ & $\begin{array}{l}\text { Encontramos cualquier tipo de } \\
\text { representación audiovisual } \\
\text { (imágenes, remix de otros } \\
\text { vídeos, dibujos animados...) }\end{array}$ & $\begin{array}{l}\text { Representación oral de la reseña. Youtuber como } \\
\text { protagonista central. }\end{array}$ \\
\hline $\begin{array}{l}\text { Edición y } \\
\text { audio }\end{array}$ & $\begin{array}{l}\text { Importancia de edición. } \\
\text { Múltiples elementos } \\
\text { audiovisuales. }\end{array}$ & Requisito: calidad del audio de la grabación. \\
\hline $\begin{array}{l}\text { Elementos } \\
\text { audiovisuales }\end{array}$ & $\begin{array}{l}\text { Cualquiera que se utilice en el } \\
\text { lenguaje cinematográfico. } \\
\text { Animaciones, ilustraciones y } \\
\text { multimedia. }\end{array}$ & $\begin{array}{l}\text { Breves textos de presentación, preguntas, efectos } \\
\text { audio y transiciones. }\end{array}$ \\
\hline $\begin{array}{c}\text { Obra } \\
\text { literaria } \\
\text { adaptada }\end{array}$ & $\begin{array}{l}\text { Se puede trabajar con cualquier } \\
\text { tipo de obra literaria desde } \\
\text { álbumes ilustrados a clásicos de } \\
\text { la literatura. }\end{array}$ & $\begin{array}{l}\text { Se puede trabajar con cualquier tipo de obra } \\
\text { literaria desde álbumes ilustrados a clásicos de la } \\
\text { literatura. }\end{array}$ \\
\hline
\end{tabular}

Todos los trabajos fueron valorados positivamente tanto por los docentes implicados, por otro alumnado a través de evaluación ciega por pares y destacados como experiencias significativas en las encuestas finales del cada curso. De una práctica aislada pasó a una práctica obligatoria en los distintos grupos de cada asignatura y se ha pasado también a otras asignaturas no recogidas en nuestro estudio.

ISL, vol. 7, 2017, págs. 55-72 ISSN: $2340-8685$
Collado Rovira, J. (2017): Booktrailer y Booktuber como herramientas LIJ 2.0 para el desarrollo del hábito lector, Investigaciones Sobre Lectura, 7, 55-72. 
Evolución del formato Booktuber: En las experiencias iniciales, 1.A. TECCAS12 y 1.B. TECCAS13, que siguen el modelo de Kuentalibros, destaca el registro académico y la formalidad de las exposiciones, incluso para obras infantiles. Frente a ellas, los vídeos 3.A. 1LLEP15, están totalmente influenciadas por los modelos youtuber actuales, que el alumnado de primero ha seguido totalmente, mostrando en algunos casos vídeos mucho más frescos, cuidados y atractivos.

Evolución de la práctica Booktrailer: En este grupo destaca la importancia de los conocimientos filológicos junto a una formación complementaria en los primeros casos: 2.A. INVTICUA13 2.B. INVTICUA14; 2.C. INVTICUA15 y 2.D. INVTICUA16. En el Máster de Secundaria confluyen egresados en Filología Hispánica y otras filologías junto a personas que han cursado otras carreras como Publicidad, Periodismo y Comunicación Audiovisual. Estas cualidades han permitido elaborar una serie importante de modelos, reseñados en distintos espacios digitales. Por ejemplo, de la primera edición 2.A. INVTICUA13 aparecen dos ejemplos como modelos de referencia en el Portfolio Lector de Pep Hernández y Silva González Goñi [https://sites.google.com/site/portfoliolector/propuestas-didacticas-generales-con-usode-tics/book-trailer]. Al igual que en la otra tipología audiovisual, la propuesta más reciente 1DLCLEI16 demuestra como el alumnado más joven está totalmente integrado en estos lenguajes audiovisuales. Además, en este caso destaca la elección de álbumes ilustrados como hipotextos centrales para los Booktrailers, ya que la representación a través de ilustraciones facilita la transformación (Tabernero, 2013).

\section{Discusión y Conclusiones}

\subsection{Nuevas vías para la LIJ 2.0}

Algunas investigadoras han incidido en el carácter epitextual de estas creaciones centrándose en los booktrailer pero muchas de esas características las podemos aplicar también a los booktuber: "La ampliación del concepto de epitexto virtual u online a los nuevos escenarios audiovisuales ha aportado una línea de trabajo imprescindible para analizar estos nuevos paratextos de promoción del libro y la lectura" (Lluch, Tabernero y Calvo, 2015, p.800).Su éxito en los jóvenes electores, confirmado por los miles de reproducciones de los canales más destacados, demuestran que son una nueva forma de promover la lectura. También podemos considerar a estos elementos como "estribillos transmedia" de la lectura (Rovira, 2016). Se pueden aprovechar tanto antes, como durante o después de la lectura de la obra literaria. Este debe ser el objetivo principal de su uso, el acercamiento a la lectura literaria y cualquier otro fin debe ser secundario frente a un nuevo tratamiento de la literatura en el aula.

Ambos son productos de creación específica que relacionan la lectura literaria con el lenguaje audiovisual y se diferencian de otras adaptaciones como los audiolibros, lecturas representadas, adaptaciones escolares, entrevistas a los autores, tráilers o las escenas de películas, siendo una práctica muy habitual en las grandes sagas. También tienen características transmedia 
puras como el Fanfiction y el Remix, con mucha influencia de las adaptaciones cinematográficas. En muchos casos no aportan nada nuevo a la narración, pero en otros casos son elementos independientes que aportan nuevos datos que amplían la lectura. (...). Los podemos considerar como un elemento de lectura social y con ellos se configura una "nueva crítica" de jóvenes lectores que conocen perfectamente las obras que tratan, aunque a lo mejor no tienen todavía un conocimiento amplio de la tradición literaria. Son herramientas de promoción lectora propias de la LIJ 2.0 y nos ofrecen enormes posibilidades didácticas. (Rovira, 2016, p.72)

En todas las prácticas analizadas siempre se ha valorado más la presencia de elementos literarios o referencias a las obras de partida o hipotextos, que puedan activar el intertexto lector de los espectadores, que la ejecución técnica o elementos multimedia que se incluyan en los mismos.

Recientes estudios nos hablan de la necesidad de nuevas alfabetizaciones en un entorno multimodal para satisfacer las nuevas necesidades lectoras (Sánchez-Claros, 2016) incluyendo el concepto de competencia visual desarrollado por Müller (2008). Aunque podemos aprovechar la infinidad de modelos que nos ofrece la red, consideramos que debemos animar a nuestro alumnado a crear sus propias narraciones audiovisuales para trabajar la "competencia en producción audiovisual" que perfectamente nos pueden servir como instrumento de evaluación si fuera necesario. En el primer caso, las reseñas audiovisuales o Booktuber, como práctica individual de cualquier lectura, en el segundo, los Booktrailer, como un trabajo grupal más elaborado y en relación con otros aprendizajes, un proyecto adecuado para trabajar en la clase de lengua el ABP.

Estas prácticas están dentro del ámbito de la $L I J 2.0$ porque suponen la participación de los lectores en la difusión de la lectura y su realización también está relacionada con el uso de otros instrumentos de Internet como blogs, wikis, redes sociales, repositorios de imágenes y de vídeo... Como destaca Pedro Cerrillo (2016, p.175) "Pero los cambios que hoy afectan a la lectura tienen también aspectos positivos que, de algún modo, contrarrestan la negativa consideración social que de ella se hace en ocasiones, y que no deben ser desdeñados, como la aparición de los booktubers". En estos momentos vivimos una etapa de expansión de estas nuevas dinámicas de interacción de la red dentro del ya citado fenómeno youtuber y según el desarrollo tecnológico pueden ser prácticas consolidadas en muy pocos años por lo que es imprescindible seguir experimentando con ellas e investigándolas. A través de los Booktrailers y los Booktubers, los formatos audiovisuales están mucho más cerca de la lectura literaria.

\section{Bibliografía}

Ambrós, A. (2015). Proyecto Kuentalibros: creación de hipertextos literarios audiovisuales. En Cleger, O. Amo J.M. De (eds.) La educación literaria y la eliteratura desde la minificción. Enfoques hipertextuales para el aula. Barcelona: ICE Universitat de Barcelona.

ISL, vol. 7, 2017, págs. 55-72 ISSN: $2340-8685$
Collado Rovira, J. (2017): Booktrailer y Booktuber como herramientas LIJ 2.0 para el desarrollo del hábito lector, Investigaciones Sobre Lectura, 7, 55-72. 
Asensi Fernández M. (2015). Booktuber como herramienta para promover la lectura en secundaria. Universidad de Alicante. [TFM].

Carbajo, S. (2014). BookTubers o la pasión por los libros. En Toyoutome [Blog]. Recuperado el 1 de octubre de 2016 de http://toyoutome.es/blog/booktubers-o-lapasion-por-los-libros/26718.

Cordón García, J.A. et al. (2013). Social Reading: Platforms, Aplications, Clouds and Tags. Oxford, Chandos Publishing.

Cordón J. A. y Gómez Díaz R. (2013). Lectura social y colaborativa, En Diccionario de Nuevas Formas de Lectura y Escritura. Madrid: RIUL-Santillana.

FUNDEU (2014). Bibliotráiler, alternativa en español para booktrailer. Fundeu. Fundación del Español Urgente. [web]. Recuperado el 1 de octubre de 2016 de http://www.fundeu.es/recomendacion/bibliotrailer-alternativa-en-espanol-parabooktrailer/.

García Rodríguez, A. y Rubio González, E. (2013). Un paseo por la blogosfera de la literatura infantil y juvenil española: de los blogs "lijeros" a Facebook. En Puntos de Encuentro. Los primeros 20 años de la Facultad de Traducción y Documentación de la Universidad de Salamanca. Salamanca: Universidad de Salamanca. pp. 51-72.

Garralón, A. (2014). Retrato del reseñista adolescente. En Revista Letras libres. $\begin{array}{lllllll}\text { Recuperado el } & 1 & \text { de } & \text { octubre de }\end{array}$ http://www.letraslibres.com/revista/letrillas/retrato-del-resenista-adolescente.

Giraldez Hayes A. (coord.) (2105). De los ordenadores a los dispositivos móviles. Propuestas de creación musical y audiovisual. Barcelona: Graó.

-Limbu, M. y Gurung, B. (2014). Emerging Pedagogies in the Networked Knowledge Society: Practices integrating social media and globalization. USA: Information Science Reference.

Literatura SM (2016). Booktubers en Literatura SM [blog] Recuperado el 1 de octubre de 2016 de https://es.literaturasm.com/somos-lectores/booktubers.

Lluch Crespo, G. (2011). Del oral, audiovisual y digital a la lectura (y la escritura) en secundaria. Madrid: Fundación SM. (Núm. 20).

Lluch Crespo, G. (2014a). Jóvenes y adolescentes hablan de lectura en la red. En Ocnos, 11, pp. 7-20. 
Lluch Crespo, G. (2014b). De booktubers o exposiciones orales para presentar una lectura. ¿Cómo lo hacemos? En Gemma Lluch [Blog]. Recuperado el 1 de octubre de 2016 de http://www.gemmalluch.com/esp/de-booktubers-o-exposicionesorales-para-presentar-una-lectura-como-lo-hacemos/.

Lluch, G., Tabernero-Sala, R., y Calvo-Valios, V. (2015). Epitextos virtuales públicos como herramientas para la difusión del libro. En El profesional de la Información EPI, 24(6), 797. Recuperado el 1 de octubre de 2016 de http://dx.doi.org/10.3145/epi.2015.nov.11.

Müller, M. G. (2008). Visual competence; a new paradigm for studying visuals in the social sciences? Visual Studies, 23 (2), 101-112.

Pacheco Alonso, B. G. (2014). BookTube. Una propuesta para el fomento a la lectura. UNAM. Recuperado el 1 de octubre de 2016 de http://issuu.com/gustavopacheco4/docs/booktubers_linea_.

Rovira-Collado, J. (2011). Literatura infantil y juvenil en internet: de la Cervantes Virtual a la LIJ 2.0. Herramientas para su estudio y difusión. Ocnos, 7, pp. 137-151. Recuperado el 1 de octubre de 2016 de http://www.revista.uclm.es/index.php/ocnos/article/view/216.

Rovira-Collado, J. y Llorens García, R. (2012). Blogs para la enseñanza de literatura infantil y juvenil en español: espacio central de la LIJ 2.0. En Perspectiva, 30 (3). Recuperado el 1 de octubre de 2016 de http://dx.doi.org/10.5007/2175795x.2012v30n3p789.

Rovira-Collado, J. (2015a). Literatura infantil y juvenil en Internet. De la Cervantes Virtual a la LIJ 2.0. Herramientas y espacios para su estudio y difusión [Tesis doctoral] Universidad de Alicante. Recuperado el 1 de octubre de 2016 de http://rua.ua.es/dspace/handle/10045/46345.

Rovira-Collado, J. (2015b). Redes sociales de lectura: del libro de caras a la LIJ 2.0. En Investigaciones Sobre Lectura ISL, (3), 106-122. Recuperado el 1 de octubre de 2016 http://comprensionlectora.es/revistaisl/index.php/revistaISL/issue/view/7.

Rovira-Collado, J. (2016). El booktrailer y el booktuber como estribillos transmedia de sagas fantásticas. En Encabo E. Martos, A. y Urraco, M. (2016) Sagas, Distopías y Transmedia. Ensayos sobre ficción fantástica, León: Universidad-Red Internacional de Universidades Lectoras. pp. 59-73.

ISL, vol. 7, 2017, págs. 55-72 ISSN: $2340-8685$
Collado Rovira, J. (2017): Booktrailer y Booktuber como herramientas LIJ 2.0 para el desarrollo del hábito lector, Investigaciones Sobre Lectura, 7, 55-72. 
Sánchez Sánchez, M. (2015). La joven mexicana que consigue que 200.000 personas se interesen por el Conde Lucanor. En El País. Recuperado el 1 de octubre de 2016 de http://verne.elpais.com/verne/2015/07/23/articulo/1437656337_736972.html.

Sánchez-Claros, J. P. (2016). Nuevas alfabetizaciones en un entorno multimodal: nuevas necesidades lectoras para un entorno textual múltiple, Investigaciones Sobre Lectura, ISL 6, 51-57. Recuperado el 1 de octubre de 2016 de http://comprensionlectora.es/revistaisl/index.php/revistaISL/article/view/153/61.

Soto Helguera L.A. (2015). Breve diccionario de nuevos términos para lectores despistados. Revista Babar [web] Recuperado el 1 de octubre de 2016 de http://revistababar.com/wp/breve-diccionario-nuevos-terminos-lectoresdespistados/.

Tabernero Sala, Rosa (2013). El booktrailer en la promoción de la lectura del relato, en Quaderns de Filologia. Estudis Literaris, vol. XVIII, pp. 211-222.

Trujillo Sáez, F. (2014). Aprendizaje basado en proyectos: formación del profesorado de Educación Permanente. En Fernando Trujillo [Blog]. Recuperado el 1 de octubre de 2016 de http://fernandotrujillo.es/aprendizaje-basado-en-proyectosformacion-del-profesorado-de-educacion-permanente/.

Trujillo Sáez, F. y Conecta13 (2015). Artefactos digitales. Una escuela digital para la educación de hoy. Barcelona: Graó.

\section{Anexos}

Anexo 1. Kuentalibros en Infantil como precedente de Booktuber.

En la Universidad XXXXXXX se propuso la dinámica específica de KuentaLibros para la asignatura Técnicas de Comunicación Oral y Escrita, optativa del Grado de Maestro en Educación Infantil. Los vídeos están disponibles en los siguientes blogs:

- 1.A. TECCAS12 Curso 2012-2013 (disponibles también en el blog del proyecto). [http://lainvencionalabordaje.blogspot.com.es/search/label/Kuentalibros]. [http://kuentalibros.blogspot.com.es/search/label/Universidad\%20de\%20Alicante].

- 1.B. TECCAS13 Curso 2013-2014 (no disponible en la web del proyecto Kuentalibros porque ya había concluido). [http://juegodemaestras.blogspot.com.es/search/label/Kuentalibro] (1) [http://juegodemaestras.blogspot.com.es/search/label/Kuenta\%20libros]

[http://juegodemaestras.blogspot.com.es/search/label/kuentalibros] (3)

Anexo 2. Booktrailer Máster de Secundaria.

Durante los últimos cuatro cursos se ha trabajado el Booktrailer con el alumnado del Máster de Formación del Profesorado, desde distintas perspectivas. En las entradas 
podemos encontrar generalmente acceso al vídeo resultado de esta práctica y al trabajo en grupo que explica la experiencia.

2.A. INVTICUA13 Curso 2012-2013. Nos basamos en obras de LIJ leídas en otras asignaturas del Máster:

" Campos de Fresas. De Jordi Sierra $\quad$ i Fabra [http://clickticlenguayliteratura.blogspot.com.es/2013/05/booktrailer-decampos-de-fresas.html]

- Las chicas del Alambre De Jordi Sierra i Fabra [http://los4lunaticos.blogspot.com.es/2013/05/booktrailer-las-chicas-dealambre.html].

- El hombrecito vestido de gris. De Fernando Alonso [http://masticandolalengua.blogspot.com.es/2013/05/pasen-y-lean.html].

- Cartas de Invierno. De Agustón Fernández Paz [http://exploradorestacticos.blogspot.com.es/2013/05/book-trailer-de-cartasde-invierno.html].

- Juul, De G. De Maeyer [http://rebelionenlastic.blogspot.com.es/2013/05/booktrailer-juul-elvideo.html].

2.B. INVTICUA14 Curso 2013-2014. Se adaptaron algunas de las lecturas obligatorias de literatura española e hispanoamericana para $2^{\circ}$ de Bachillerato en la Comunidad Valenciana:

- Luces de Bohemia. De Ramón María de Valle-Inclán (2 grupos). [http://filolotics.blogspot.com.es/2014/05/book-trailer-luces-de-bohemia.html], [http://lainnovadoraeducacion.blogspot.com.es/2014/05/luces-de-bohemia 26.html].

- Antología Poética. De Miguel Hernández. [http://esticboig.blogspot.com.es/2014/05/booktrailermiguel-hernandez_26.html].

- La casa de los Espíritus. De Isabel Allende (2 grupos). [http://fantas-ticland.blogspot.com.es/2014/05/la-casa-de-los-espiritus-booktrailer.html],

[http://ellaberintodeulises.blogspot.com.es/2014/05/ya-esta-aqui-ya-llego.html].

2.C. INVTICUA15 Curso 2014-2015. Se permitió que cada grupo eligiera una obra de la literatura española apropiada para la Educación Secundaria:

- Los niños tontos. An Anaría [http://malditasesperpenticas.blogspot.com.es/2015/05/booktrailer-de-los-ninos-tontos-deana.html].

- La tierra de Alvargonzález. De Antonio Machado [http://profetics2015.blogspot.com.es/2015/05/trabajo-del-booktrailer_27.html].

- La casa de Bernarda Alba. De Federico García Lorca [http://nopuedovivirsintics.blogspot.com.es/2015/05/booktrailer-la-casa-de-bernardaalba_25.html].

" El Lazarillo de Tormes [http://ticsfanatics.blogspot.com.es/2015/05/booktrailer-lazarillo-detormes-tics.html].

- Marina de Carlos Ruíz Zafón [http://posttics.blogspot.com.es/2015/05/2.html].

- La vida es sueño. De Calderón de la Barca [http://elpoemademiotic.blogspot.com.es/2015/05/trabajo-escrito-sobre-el-booktrailer.html].

ISL, vol. 7, 2017, págs. 55-72 ISSN: $2340-8685$
Collado Rovira, J. (2017): Booktrailer y Booktuber como herramientas LIJ 2.0 para el desarrollo del hábito lector, Investigaciones Sobre Lectura, 7, 55-72. 
2.D. INVTICUA16 Curso 2015-2016. Con motivo de los centenarios relacionados con grandes hitos de la literatura (Miguel de Cervantes, William Shakespeare o Roald Dahl) se propuso adaptar obras clásicas relacionadas con estas u otras efemérides, aunque luego se incluyeron otras obras.

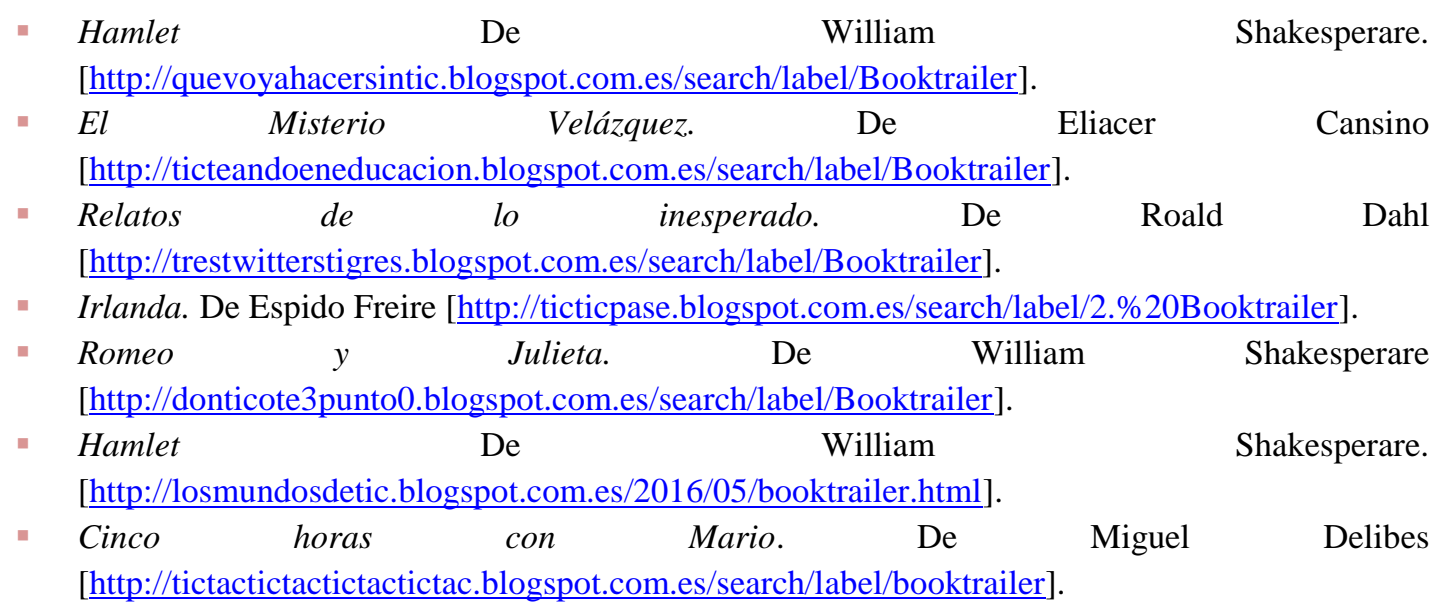

\section{Anexo 3. Booktrailer y Booktuber del alumnado universitario de primer curso}

También durante el curso 2015-2016 se realizaron dos prácticas concretas con el alumnado de primer curso, para comprobar que este tipo de formato es muy adecuado para el alumnado más joven y que este demuestra el interés y los conocimientos técnicos para ofrecernos prácticas muy concretas:

3.A. 1LLEP15 Lengua y Literatura Española para la Enseñanza Primara. Primer curso del Grado de Primaria.

En la práctica "Hitos de la literatura en español” había que hacer una reseña de un clásico de nuestra literatura. Al alumnado se le propuso hacer individualmente las reseñas audiovisuales según el modelo de Booktuber hablando de obras como El perro del hortelano, Cárcel de Amor, Marianela o Las bicicletas son para el verano. El formato novedoso y la motivación de una práctica diferente nos ofrecen unos resultados muy interesantes.

- Lista de reproducción Booktuber 1LLEP15 con nueve ejemplos significativos. [https://www.youtube.com/playlist?list=PLDY6-ZydXtF4XUj2nV2dZWxy-v_n_eK2E].

3.B. 1DLCLEI16 Didáctica de la Lengua y la Literatura Castellana en Educación Infantil. Primer curso del Grado de Infantil.

Entre las múltiples prácticas de animación a la lectura para el aula de Educación Infantil se propuso adaptar en grupo alguna de las lecturas recomendadas, principalmente álbumes ilustrados para presentarlos a su futuro alumnado. Entre las distintas adaptaciones encontramos entre otros: Oh!, Nadarín, Quiero mi chupete, Ferdinando el 
Toro, Orejas de Mariposa, Óscar y el León de Correos, Cangura para todo, La pequeña oruga glotona, Sapo y Sepo son amigos, Frederick, El poderoso llanto de Mateo o Un puñado de besos.

- Lista de reproducción Booktrailer LIJ 1DLCLEI16 con veinte ejemplos significativos. [https://www.youtube.com/playlist?list=PLDY6-ZydXtF47TXeTktRDH2rSRWFnuUpb].

El alumnado de primer curso demostró un conocimiento técnico y una capacidad de síntesis adecuada para ofrecernos unos vídeos adecuados para el aula de Educación Infantil.

ISL, vol. 7, 2017, págs. 55-72 ISSN: 2340-8685
Collado Rovira, J. (2017): Booktrailer y Booktuber como herramientas LIJ 2.0 para el desarrollo del hábito lector, Investigaciones Sobre Lectura, 7, 55-72. 